\title{
Music as a Modus of Accomplishing Epochē: Four Theses on Musical Phenomenology*
}

In memory of Dimitar Zashev (1948-2018) and Andrey Leskov (1960-2020) — two Bulgarian philosophers who left indelible marks in the study of phenomenology.

\author{
Kristina Yapova \\ Bulgarian Academy of Sciences, Sofia, Bulgaria
}

\begin{abstract}
How can music be a modus of accomplishing what Husserl calls "a radical, skeptical epoch $\vec{e}$ ", that is, a way of refraining from judgment about all that is to be known? In order to answer the question, we have to first submit music itself to the act of epoche. This will allow us to get free from the widespread opinion that music is only an art, and to understand it in a broad sense, namely as a sphere of Being. This sphere is founded on the tone which, on its part, is thinkable not as an expression of the number (as in the Pythagorean tradition) or a medium for voicing, supplementing, or accompanying words, but as a primary essence enabling us to reach the truth of Being in a direct and immediate way. Hence, music provides an advantage for the one who chooses it as a way of accomplishing epochē. In providing immediate access to the truth of all thinkable things and of Being itself, it releases him from the necessity to cover any distance to it by passing through concepts, notions, and ideas in relation to which he is required to exercise the discipline of epochè.
\end{abstract}

Keywords: music, epochē, tone, hearing, reason in music, musical reason

The present research places its focus on the cognitive opportunity which music contains in itself and through which it opens up access to the truth of Being. Musicology today needs this research perspective if it is to regain its right to be a philosophical science in the truest sense, i.e., a science that utilizes the musical resources embedded in philosophy itself. Attention to these resources, indubitable to Plato who called philosophy "the greatest kind of music" (Phaedo 61 a), has gradually waned in later eras. This is a process which goes hand in hand with the differentiation of the science of music and its becoming a private discipline of philosophical knowledge and later on, with its internal division into increasingly specialized disciplines, such as musical acoustics, aesthetics, ethnology, psychology, etc.

Of course, musicology today cannot unreservedly trust this Plato's thought (so familiar and so often cited by researchers), but it can extract from it certain perspectives needed for its own priorities. And in order to extract them, musicology must subject this thought (along with other thoughts scattered throughout history) to what Husserl calls a radical, skeptical epoche- - an act "which places in question all his hitherto existing convictions,

\footnotetext{
* Acknowledgement: The research was carried out with the financial support of the Scientific Research Fund attached to the Bulgarian Ministry of Education and Science within the framework of scientific project No. 10/6, 15.12. 2016 "Contemporary musical composition, theory and philosophy".

Kristina Yapova, DSc, Professor, Institute of Art Studies, Bulgarian Academy of Sciences, Sofia, Bulgaria.

Translated by Mihail Lukanov.
} 
which forbids in advance any judgmental use of them, forbids taking any position as to their validity or invalidity" (Husserl, 1936/1970, p. 76). Husserl adopts this act, rethinking it within his transcendental phenomenology, from Descartes' doubt, explicitly stated in the first of the principles of human knowledge put forward by that thinker of 17th century: "in order to seek truth, it is necessary once in the course of our life, to doubt, as far as possible, of all things" (Descartes, 1644, p. 25). To the author of "The Crisis", Cartesian doubt is so fundamental that he almost literally reiterates Descartes' statement in order to give it its due:

Once in his life every philosopher must proceed in this way; if he has not done it, and even already has "his philosophy", he must still do it. Prior to the epoche "his philosophy" is to be treated like any other prejudice. (Husserl, 1936/1970, p. 76)

The epoche offers the philosopher who undertakes it an opportunity to get to the deepest sphere of Being,

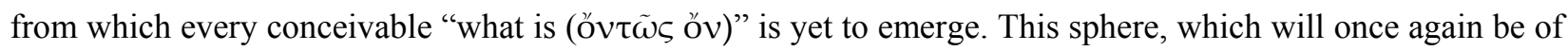
paramount importance for transcendental phenomenology, is described by Descartes in his ninth principle of human knowledge:

By the word thought, I understand all that which so takes place in us that we of ourselves are immediately conscious of it; and, accordingly, not only to understand (intelligere, entendre), to will (velle), to imagine (imaginari), but even to perceive (sentire, sentir), are here the same as to think (cogitare, penser). For if I say, I see, or, I walk, therefore I am; and if I understand by vision or walking the act of my eyes or of my limbs, which is the work of the body, the conclusion is not absolutely certain, because, as is often the case in dreams, I may think that I see or walk, although I do not open my eyes or move from my place, and even, perhaps, although I have no body: but, if I mean the sensation itself, or consciousness of seeing or walking, the knowledge is manifestly certain, because it is then referred to the mind, which alone perceives or is conscious that it sees or walks. (Descartes, 1644, pp. 29-30)

Due to the complexity and large scale of the problem posed, it will be considered here by means of theses. First and foremost, the question of whether music has any cognitive ability should be raised, hence whether it can be conceived of as a way of immediate awareness of "what is taking place in me".

This makes it obligatory to first call into Cartesian doubt two things. The first of them is related to the first thesis:

\section{First Thesis: The Concept of Music According to Musical Essence}

\section{What Is Music?}

This is the first question in regard to which the discipline of refraining from judgment must be exercised. The most common belief is that music is an art. Those who share it (and they are people of all professions, including musicians) will not give it up easily. No additional knowledge of history could dissuade them, e.g., that prior to being defined as an art, music used to be a science; that its boundaries were firmly established by the Pythagoreans, who made great effort to justify the nature of what this science was concerned with (according to the various historical emphases, the sounding number, or the numerical sound); that the place of music among the philosophical sciences did not waver throughout the Middle Ages when the word musica was an umbrella term for disciplines and subdisciplines brought together by the general method of music theory, while the world of sound, of musical practice did not even have a unified name and broke down into specific genre designations (Dyer, 2007) ${ }^{1}$; that the most sagacious philosophers of the seventeenth century thought of

\footnotetext{
1 "In the Middle Ages, the term musica applied properly to the speculative science that considered proportional relationships, while cantilena and cantus referred to sounding music", p. 3.
} 
music in a way that did not deviate from its Pythagorean basis (the number); that it was only with the autonomous musical aesthetics of the 19th century that the idea of music as an art in the strict sense of the word

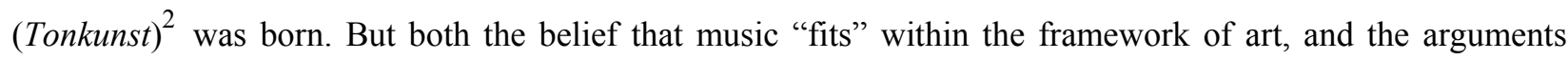
entrusted with the task of expanding or transcending this framework require an equal degree of distancing if the one raising the question "What is music?" is to achieve an answer in a pure form without reaching out to any notion available in his knowledge repository. "Once in his life" even the modern musicologist should assume the stance enabling him to say that he does not know what music is.

First of all, it is necessary to situate the concept of "music" within limits in which it safeguards its effectiveness, i.e., limits that allow for music itself to be hold as a thinkable "what is". As something pertaining to thought and disciplining it, the concept must stop before the point beyond which it dissipates, since it returns the thing described back in a state of an unthinkable amorphism. It must therefore become an ultimate concept, i.e., one that reaches the cause of the very thing it describes, its raison d'etre, removing from itself all further content that seeks to force its way into it through questions in relation to which thought is not capable of making credible judgments. Here the proposition regarding the unity of Being and knowledge reminds us that we only have access to this side of music and we call "music" only what we ourselves have objectified as music.

The first cause which has brought music to life (hence the cause that holds the very concept of "music") is the tone. The tone is the only thing that those ignorant of "what music is" know about it. Because it is its essence, its most intimate quality without which any idea of music would be ruined, as it would be deprived of the limit through which music itself exists.

\section{Non-rational and Rational Nature of Music}

Definitions of the nature of music as human music ${ }^{3}$ have oscillated in history within the range between "non-rational" and "rational". While the idea of the unbreakable link between man and music runs like a red thread throughout the centuries, the interpretation of the relationship between the non-rational and rational in music has been lowering the scales to one side or the other. In ancient theories of ethos, the link between music and man (manifested in its ability to influence him by moving him towards various states, including driving him insane) was explained by a structural similarity of music to all "parts" of the human soul, first and foremost to the unconscious parts, and then to the rational part. Challenging these ancient theories, Nietzsche relies on the ecstatic nature of music, which denotes man's movement beyond himself into the ex-sphere of Being preceeding any individualization. However, the distinction between such non-rationality, or rather pre-rationality of music, and that non-rationality which occupies all territory of music (thus rejecting any content of reason in it) is full of meaning and cannot be neglected.

If philosophy "in our time (Husserl refers to his modernity from which we have been separated for almost a century - my note) threatens to succumb to skepticism, irrationalism, and mysticism" (Husserl, 1936/1970, p. 3), how much more is the knowledge of music threatened to become such a victim, given that all the range of non-rational resources of music itself has to be eventually acknowledged? It is therefore necessary while

\footnotetext{
2 Edward Hanslick in "The Beautiful in Music" (especially Chapter 3, Orig. title: Vom Musikalisch Schönen, 1854) clarifies the reasons for musical aesthetics to be a differentiated modern science, discovering them in the aú $\tau$-vouot of music itself.

3 The serious arguments which allow for the assertion of the statement (from a phenomenological point of view) that "music" is only human music are based on the proposition that man being endowed with logos participates in the very act of constituting the tone. All other assumptions that the singing of birds or the sounds of other living beings could be included in the definition of "music" are to be rejected, as they can only be accidental coincidences with the acoustic pitch of tones.
} 
recognizing all non-rationality in music to see it at the same time as a broad sphere where human reason finds its first delineations and its first form, namely, the form of musical reason. And if we dare to claim that adequate, proper, and consubstantial knowledge of music is possible at all, this statement must be based on its own nature - a nature that is not only saturated with non-rational impulses, but is in equal degree founded on reason. This reason-founded nature music owes to its inherent quality, namely the tone.

It is in $i t$ that the preconditions for the possibility of musical knowledge truly reside - a distinct knowledge due to the distinct recognizability of each tone (with its specific pitch) and of tone movement (with its discrete relationship between tones). Music has its rational nature and it has it together with the non-rational one.

\section{Second Thesis: Reason in Music or Musical Reason}

The non-rational nature of music must be taken as a horizon where musical reason acts and where it constantly reclaims itself. On this proximate horizon for thinking as a subjective act by which we immediately realize everything that "takes place in us" (Cartesian cogitatio), the action of musical reason unfolds in specific conditions. Before considering them, it is necessary to clarify the distinction made in the title of this paragraph.

\section{Reason in Music}

Today, the words "reason" and "music" when placed side by side provoke astonishment, often resistance. The modern age assumes that reason is connected with verbal language, speech, concepts, and ideas, and music only enters into a relationship with it, if at all, by voicing, supplementing, or accompanying them. However, history provides many more solutions to the problem of the relationship between music and reason. The first of them belongs, as is well-known, to the Pythagorean tradition. Plato states it most clearly: The principle by which the Demiurge creates the soul of the world is rational and at the same time musical. There is order in the cosmos determined by reason; order means that everything is rationally connected with everything else, and the connection is musical, i.e., made by harmony. Harmony sets the exact relationships (proportions) between things. Reason in music goes through the number, not the words. Thus, however, its act is again subordinate, not a primary one.

The computability of music remains the determining criterion for the presence of reason in it until the 17th century, the century which is rightly called mathematical (Zashev, 2010) ${ }^{4}$. In their writings on music, Leibniz and Descartes indicate that they recognize themselves as Pythagoreans: the former (in his famous definition stating that music is a secret arithmetical exercise that the soul performs unconsciously [Leibniz, 1712, as cited in Schäfke, 1964, p. 289]) and the latter (in the strict adherence to the Pythagorean principles in his Compendium musicae) employ the numerical nature of music in favor of the mathematical paradigm of their age.

The fact that both Leibniz and Descartes are thinkers who not only do not view reason in a traditional and conventional way, but on the contrary, devote the greatest interest to it by advancing the idea of reason far ahead in an unprecedented way, challenges us to think about whether we can, in one fell swoop, subsume music entirely under the numerical solution of the music—reason relationship ${ }^{5}$. Do we not find in the philosophy of

\footnotetext{
${ }^{4}$ Zashev emphasizes that for early Descartes the "security" of "a universal and unified science" must be of "a mathematical type", p. 29.

5 Even in the following centuries of the Modern Era, this type of reasoning continued to dominate. Between the 18th and at least until the middle of the 20th century, it coexisted with another tendency, the increasing acceleration of which is very noticeable, namely denying music any connection with reason. If, after all, such a connection is recognized, it passes under the sign of a quietly made change expressed in the fact that one side of the connection is no longer called reason, but rationality. In turn, rationality in music is understood as a regularity - an objective regularity which subjective creativity adopts, follows and builds on. The objective tone-ear relationship was affirmed by Hanslick as an axiom (i.e., a true statement that requires no proof), but pushed back to...the Pythagorean postulates.
} 
these thinkers ideas in the context of which we can position music in such a way as to arrive at a different understanding of the relationship between music and reason? One such strong idea of Descartes is precisely the idea of doubt with its "hitherto unheard-of radicalism" (Husserl, 1936/1970, p. 76). Proceeding from it, we can trace such a musical potentiality internally belonging to reason and not reducible to anything else, with the realization of which reason itself expands its cognitive limits.

\section{Musical Reason}

This Cartesian idea from which Husserl derives his radical, skeptical epochē makes it possible to ground the thesis about reason in music, understood not only as a predetermined objective rationality substantiated by the computability of musical sound, but also and precisely as musical reason. One who does not know what music is has to penetrate "into the sphere of being which is prior in principle to everything which conceivably has being for me, and to all its spheres of being - as their absolutely apodictic presupposition" (Husserl, 1936/1970, p. 78). In doing so, he can make an initial division of the ability of reason to operate in two moduli, namely the rational-discoursive modus and musical modus of reason. Now the question is: Does not the conception of such a positive connection between music and reason, which would acknowledge the existence of a musical modus of reason, contradict Cartesian reason?

If we use a cliché with a self-ironic gesture (just as any cliché could be used in the context of the epochē theme), we can say: By an irony of fortune, the Cartesian epochè requires that it be applied to Cartesian reason as well. We can also say: In the rhythm of fortune, the thing that Descartes warns about (namely that the ideas of Plato and Aristotle circulate in a form very different from the way they were expressed by the two thinkers - a form on which too many prejudices were imposed) is also relevant to Cartesian reason, which has taken on the stamp of later interpretations. It is burdened by the prejudice that reason, being an organon of thinking capable of prescribing clear rules for it, can be reduced to its rational-discoursive type which works with concepts. But to accept this prejudice would be to block the pathway back to that sphere of Being which, preceding every single conceivable "what is", precedes the whole realm of concepts which is yet to be constructed. It is in that sphere of Being - a sphere which is the absolutely apodictic presupposition for any relation of concept-based reason to any conceivable "what is"-where the musical potentiality of reason resides; it is here that the action of reason in its musical modus begins.

The proposition that reason finds in music a modus ensuring an immediate access to the sphere of Being which precedes every conceivable being, is based on a specific ability, namely the tone ability (a concept that sublates and rethinks the harmonic ability of ancient and medieval music theories). This ability provides reason with a manner of referring "what is" to perception and awareness. This manner, which from within and gradually fills up the musical modus of reason, has one peculiarity.

\section{The Tone-A Condition for the Possibility of Musical Knowledge}

The tone, like anything else, becomes a phenomenon in the dynamic between "it itself" and our perception and awareness of it: Thus, it reveals its essence to us, becomes a phenomenon of consciousness. Among the various regimes of describing the tone (physical, psychological, mathematical, and musical-theoretical), the phenomenological one begins with the heard tone. Musical knowledge becomes "manifestly certain" in that it constantly refers to the heard (perceived by the senses and grasped by reason) tone, which is the basis of anything thinkable as music. The force which has propelled the tone and led it to the state of being a

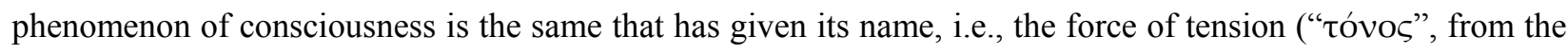




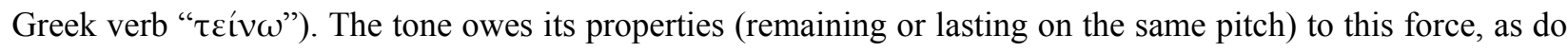
these of tone movement based on the discrete relationship between tones. The activity of musical reason begins with the heard tone. If the tone is the ontological precondition for the action of reason in its musical modus, then the access to the deepest sphere of Being in question, which this action receives, will be open in a place preceding that in which this access is provided for the rational-discoursive modus of reason. This place is hearing. Understanding hearing as an existential will make it clear that the musical ability of reason has an independent action of its own, which takes place in a sphere preceding that of discoursive rationality.

\section{Third Thesis: Hearing as an Existential}

We hear only ourselves. For we are gradually becoming blind to the outside. Whatever else we still shape leads back around us. It is not exactly as readily individual, not exactly as hazy, hovering, warm, dark, and incorporeal as my feeling of always being just by myself always just conscious. It is a stuff, an alien experience.... But the note flares out of us, the heard note, not the note itself or its forms. Yet it shows us our way without alien means, shows us our historically inner path as a flame in which not the vibrating air but we ourselves begin to tremble, and throw off our coats. (Bloch, 2000, p. 34)

In a narrow sense of the word, the act of hearing denotes an ability to understand what has been heard, i.e., an understanding through listening, and in the broadest sense- a possible position or disposition of man in existence which opens before his thought an access to Being. What is distinctive about hearing taken in this broadest sense is that it is a passive or pathos-laden position. Passivity points not only to the existential thrownness (Geworfenheit) of man, but also to the passive way in which man gains this access. Fully committed to what he is listening into, he comprehends it, being turned towards the same direction and following the course of its own revealing before him. In other words, he grasps what he is grasped by.

Hearing is an existential (dis)position of man which allows him to achieve the truth of Being forwardly and immediately as self-revealing in the tone and tone movement. Here he perceives truth as something approaching, drawing near to him, delivering more and more new moments of its essence. These moments arise out of the spaces between the tones, out of the gaps of intervals (diastemas) and they are what make the tone stasis to be the only possible one. For the one who hears, what has arisen is unmistakably recognizable as true, insofar as it is the result of a first synthesis - the synthesis between every moment which truth reveals from its essence for the first time before him, and the transformation of this moment into a discovery by man.

The immediate proximity of musical reason to the broad sphere of the non-rational from which it incessantly conquers itself provides an advantage for the musical epoche. If the epoche is at all a way of reaching the sphere of Being, which precedes every conceivable being, there is no need for the musical epochē to cover any distance back in order to arrive there, because the modus of reason in which it takes place remains in the immediate vicinity of this very sphere of Being, i.e., the sphere of "the absolutely apodictic self-evidence 'I am"” (Husserl, 1936/1970, p. 77) ${ }^{6}$. Here, where there are not yet those "things" to which thought must apply the discipline of withholding judgment, musical reason carries out its action not by rejecting, but by preventing the process of their becoming obstacles standing in the way of thought and blocking its access to the truth of Being, which reveals itself in the midst of non-truth.

Thus, our third thesis in its positive content states: music as a modus of epoche precedes the others. And this is due to the specific disposition that determines the action of musical reason, namely the disposition of mutual directionality between what is revealing itself in hearing and the one who hears. Such a disposition does

${ }^{6}$ During "the universal epoche", this sphere of the only self-evidence is "at my disposal" (Ibid.). 
not deprive the one who undertakes the musical epoche of the self-evidence "I am", but rather commits it to hearing with its specific way of understanding - an understanding which man achieves in passivity being completely defenseless before what approaches him, overtakes him, catches up to him, storms upon him, encompasses him and urges him to comprehend it. The understanding in the place of hearing is blind (and yet based on reason) as it is by definition deprived of the opportunity to gaze into what stays opposite and requires the one who gazes into it to deal with, refrain from, and reject any available arsenal of knowledge about it. It is, however, endowed with the capacity for listening into the thing which, gradually emerging and acquiring the form of a message of Being, reveals itself for the first time before the man of hearing, gets into him, passes through him and expects to be announced by him.

The proposition advanced by Husserl (according to which transcendental subjectivity is the common basis of the relationship between what is perceived by the senses and consciousness) retains its validity in the field of music. However, the way in which this relationship takes place here is specific. It aims at making use of the cognitive potential contained in the toneness of the tone with its two conditions - unity and diastematicity; it must activate the musical reflection of consciousness through which the transcendental synthesis necessary for every cognitive act is realized; it must let the tone achieve its being-and-cognitive unity and become a heard tone.

\section{Fourth Thesis: The Relationship Between the Musical and the Rational-Discoursive Modus}

When reason chooses to follow its inner musicality, it enters a domain still untouched by ideas and concepts. Here "still" suggests that its place of action lies before that of rational-discoursive reason. We can now ask the question of how (quo modo), or the manner of action of musical reason.

The action of reason in its musical modus is a tone-based action subjected to the two conditions of toneness, namely unity (stasis) and diastematicity (intervality). This action by which consciousness moves forward directly (i.e., without the mediation of number, word, and idea) towards the essence of all that it will get to know begins with hearing and remains in the place of hearing. Here, in his passive existential disposition, man has committed himself entirely to the truth of Being which incessantly reveals itself to him. Commitment denotes openness to this truth - an openness which is his response to the unconcealment (Unverborgenheit) of Being itself. In such a position of openness he perceives the presence of Being in everything that appears before him as a first event (co-Being, or Mitsein), as a movement not yet frozen, not yet subject to capturing by any constructed conceptual network.

The modus as such is fullness $(\pi \lambda \eta \dot{\varrho} \omega \mu \alpha)$ : Man is completely involved in it. That is why the action of the musical or of the rational-discoursive modus is an independent action starting out from the same sphere of Being, but carried out in a different way. The two moduli do not combine; they relate to each other in the paradigm of "either... or...", because it is precisely the fullness of each that opens access to Being. Each of these fully entails human reason and determines its behaviour. Both one and the other begin with the event, which can be presented as a bilateral event only analytically (in reality the two sides are in unity): On the one hand, the incessant self-revealing of the truth of Being, and on the other, its constant uncovering by man. From this point onward, the work of either the musical or rational-discoursive reason is yet to continue, and it will continue to the end. Does this mean that there is no connection between them? Within modus-related conceivable limits-yes. What, then, is the infinity at which the two parallel lines intersect?

We gather that this is a horizon - the infinite horizon of reason. Only on this horizon does the statement (the centre of our fourth thesis) that for all their incompatibility with each other the relationship between the 
two moduli is possible make sense. It is of such a kind whereby neither of moduli changes course to enter into the realm of the other, but human reason with its infinite potentialities to penetrate all spheres of Being, may keep and consult what it has once achieved through one or the other. The way before the action of musical reason is solely musical one: it cannot be repeated or borrowed by anybody who dwells in the other modus. However, what has once arisen out of the diastemas of the tone movement and has been conceived as it is by the one listening into it, cannot vanish. It takes shelter in the foundations of the soul and remains there as a cognitive experience.

\section{Conclusion}

Recognizing a musical potentiality of human reason gives at least two advantages to the one who choose to follow it: the first is concerned with understanding music itself, the second, with the knowledge of everything that may have Being for him through music. As for the first, it makes it possible to overcome a contradiction always present when we want to know a given essence (music in this case) with the aid of another kind of essence (through the work of conceptual or rational-discoursive reason). Because how could music possibly manifest itself as a phenomenon for a consciousness which has rejected its own musicality and operates with common tools with which it approaches another essence? In comprehending the principle of similarity (so necessary for Plato and Aristotle) not just as an objective structural similarity (enabling certain harmonies to be connected with certain states of the soul), but as a cognitive principle allowing music (as a conceivable entity) to be known properly and adequately, we will make way for the action of the human reason in its musical modus.

As for the second advantage, it is directly related to the theme of the present text and lies in the unique capacity of music for accomplishing the epoche. As a modus in the fullness of which reason can act, the musical modus allows the essence of all that is to be known to be reached in a place and at a time before any knowledge-laden baggage of ideas, notions, and concepts (in relation to which the discipline of epoche is to be exercised) has been accumulated.

\section{References}

Bloch, E. (2000). The spirit of utopia. (A. A. Nassar, Trans.). Stanford, California: Stanford University Press.

Descartes, R. (1644). Principia philosophiae (The principles of philosophy). (J. Veitch, Trans.). Retrieved October 10, 2020, from https://www.fulltextarchive.com/page/The-Principles-of-Philosophy $1 /$

Dyer, J. (2007). The place of musica in medieval classifications of knowledge. The Journal of Musicology, 24(1), 3-71.

Husserl, E. (1936/1970). Die krisis der Europäischen wissenschaften und die transzendentale phänomenologie (The crisis of European sciences and transcendental phenomenology). (D. Carr, Trans., with an Introduction). Evanston: Northwestern $\begin{array}{llllll}\text { University } & \text { Press. } & \text { Retrieved } & \text { October } & 10, & \text { 2020, }\end{array}$ https://epdf.pub_the-crisis-of-european-sciences-and-transcendental-phenomenology-an-introduction.html

Schäfke, R. (1964). Geschichte der Musikästhetik in Umrissen. Mit einem Vorwort von Werner Korte. (2 Aufl.). Tutzing: Schneider.

Zashev, D. (2010). "Az mislja" v kartezianska i transcendentalno-filosofska interpretazi ("I think" in Cartesian and transcendental-philosophical interpretation). In Images and patterns: Configurations of the formless (pp. 23-67). Sofia: St. Kliment Ohridski University Press. 